\title{
Carta de Quito: Cobertura Universal, Medicina de Família e Comunidade e participação social
}

\author{
Letter of Quito: Universal Coverage, Family and Community Medicine and social participation \\ Carta de Quito: Cobertura Universal, Medicina Familiar y Comunitaria y participación social
}

\author{
Assinam o presente documento, datado de 12 de abril de 2014 na cidade de Quito, Equador: \\ Carina Vance. Ministério da Saúde do Equador. República do Equador. \\ Augusto Barrera. Distrito Metropolitano de Quito (DMQ), Equador. \\ Michael Kidd. Organização Mundial de Médicos de Família (WONCA). Austrália. \\ Manuel Pena. Organização Panamericana da Saúde/Organização Mundial da Saúde (OPS/OMS). Equador. \\ Maria Inez Padula Anderson. Confederação Ibero-americana de Medicina Familiar (CIMF). Brasil. \\ Edgar León. Presidente V Cumbre Iberoamericana de Medicina Familiar. Equador.
}

Durante os dias 11 e 12 de abril de 2014, na cidade de Quito, Equador, foi realizada a V Cumbre Iberoamericana de Medicina Familiar com o tema: "Cobertura Universal, Medicina de Família e Comunidade e Participação Social".

Este evento, organizado pelo Ministério da Saúde do Equador, a Organização Mundial de Médicos de Família (WONCA), Confederação Ibero-americana de Medicina Familiar (CIMF), a Sociedade Equatoriana de Medicina Familiar (SEMF), o Município do Distrito Metropolitano de Quito (DMQ) e a Organização Panamericana da Saúde/Organização Mundial da Saúde (OPS/OMS), teve como objetivo contribuir para o fortalecimento das políticas de saúde no campo da Atenção Primária e da Medicina de Família na Ibero-América.

Representantes dos Ministérios da Saúde da Ibero-América, representantes da WONCA, representantes da WONCA Ibero-americana-CIMF, representantes da SEMF, representantes de saúde de governos municipais do Equador e de outros países Ibero-americanos, coordenadores/as de programas docentes de Medicina de Família, delegados/as da sociedade civil e representantes da OPS/OMS, analisaram os temas relacionados a seguir:

1. A Cobertura Universal e a Medicina de Família e Comunidade.

2. A participação e comunicação social para a Medicina de Família e Comunidade e a Atenção Primária à Saúde (APS).

3. A formação de médicos e médicas de família na Ibero-América.

4. A certificação e acreditação profissional.

5. A produção e difusão de conhecimentos em medicina de família e comunidade na Ibero-América. 
Como resultado desta análise dos grupos de trabalho formados por especialistas nas áreas mencionadas das organizaçóes convocadas e as instituiçôes que certificam esta Cumbre, foram geradas as seguintes definiçốes e recomendações:

\section{Definições}

\section{Cobertura Universal}

É a garantia do exercício do direito à saúde para todos e todas, fornecido por um sistema integral e integrado de base estatal com financiamento público, que possibilita o acesso aos serviços, de maneira equitativa, igualitária, oportuna, integral e de qualidade, baseado nos princípios de solidariedade e participação social, tendo a Atenção Primária como eixo do cuidado, com médicos e médicas de família e comunidade nas equipes de saúde, assegurando o primeiro contato e o acompanhamento contínuo, centrado na pessoa em seu contexto familiar e comunitário, em conformidade com as necessidades de saúde que apresentam no curso de suas vidas.

\section{Medicina de Família e Comunidade}

A Medicina de Família e Comunidade é uma especialidade essencial para garantir a sustentabilidade dos sistemas de saúde. Fornece cuidados centrados na pessoa em seu contexto familiar e comunitário de forma contínua, independentemente de sua idade, sexo, condição socioeconômica ou de saúde, integrando no processo de atenção os fatores físicos, psicológicos, sociais culturais e existenciais que contribuem no processo saúde-doença.

O médico ou médica de família tem uma responsabilidade profissional e social com a sua comunidade. Desempenha seu papel por meio da promoçáo da saúde, a prevenção da doença e a prestaçáo de cuidados clínicos assistenciais, de reabilitação e paliativos; atua de acordo com as necessidades de saúde, respeitando a diversidade cultural e otimizando os recursos disponíveis na comunidade. Deve responsabilizar-se pelo desenvolvimento e manutenção de suas competências, valores e equilíbrio pessoal, como base para a prestação de cuidados efetivos e seguros. A Medicina de Família e Comunidade é uma ferramenta chave para o desenvolvimento e a manutenção da saúde dos povos.

\section{Recomendações}

1. Reconhecer o conceito da Cobertura Universal para que transcenda os aspectos técnicos do financiamento sanitário e incorpore os princípios de equidade, igualdade e solidariedade, no direito à saúde e na responsabilidade dos governos para estabelecê-la.

2. Gerar políticas e promover as mudanças necessárias para que os sistemas de saúde da Ibero-América alcancem a Cobertura Universal.

3. Reconhecer a especialidade de Medicina Família e Comunidade como parte da equipe de APS para alcançar a Cobertura Universal e o acesso efetivo da populaçáo aos serviços de saúde a partir de um olhar integral e integrador da APS.

4. Posicionar a especialidade de Medicina de Família como integrante fundamental dos sistemas de saúde que permitirá a implementar a Atenção Primária nos países da Ibero-América.

5. Reconhecer que os indicadores para medir o avanço à Cobertura Universal devem incluir aqueles relacionados com o fortalecimento da APS, incorporando o financiamento público, o acesso aos serviços, a qualidade dos mesmos, o número de equipes de saúde e o número de especialistas em Medicina de Família e Comunidade, com formaçáo e capacitação qualificadas, envolvidos nestas equipes.

6. Incluir nos indicadores parâmetros de qualidade em relação à estrutura físico-funcional das unidades de saúde do primeiro nível, a fim de proporcionar que os médicos e médicas de família e comunidade possam alcançar a excelência clínica em sua capacidade resolutiva.

7. Promover que nos sistemas de saúde da Ibero-América a proporção de especialistas em Medicina da Família e Comunidade em relaçáo ao total de especialistas alcance $50 \%$ e que este valor seja um indicador para o alcance da Cobertura Universal. 
8. Consolidar a participação cidadã na saúde como um direito que promove a ação dos atores sociais na tomada de decisões e gestão pública da saúde para incidir nos determinantes sociais da saúde com igualdade e equidade.

9. Facilitar a articulação intersetorial dos grupos de agentes comunitários de saúde.

10. Promover a educação em saúde e o intercâmbio de experiências nacionais e internacionais, utilizando meios de comunicação de massa, tais como rádio, televisão, periódicos, websites, Facebook, Twitter e outros.

11. Integrar a participação e comunicação social ao setor acadêmico desde o estudante até a pós-graduação.

12. Advogar pela criação de uma aliança internacional permanente de participação e comunicação social para a Medicina de Família e Comunidade.

13. Promover que os governos, os gestores de saúde e de educação tomem decisões e desenvolvam políticas que permitam o fortalecimento de um primeiro nível de atenção qualificado, de maneira a contrariar os interesses antagônicos que nos últimos 100 anos privilegiaram a constituiçáo de sistemas de saúde centrados na atenção hospitalar e na medicina superespecializada.

14. Apoiar a formação do talento humano em Medicina de Família e Comunidade, sua capacitação contínua e de qualidade e sua justa remuneração.

15. Reconhecer que a certificação e acreditação profissional em Medicina de Família e Comunidade permite o fortalecimento da qualidade de atenção no tempo e estimula a atualização do profissional.

16. Promover a pesquisa e a formação contínua como elementos fundamentais para manter o nível profissional dos médicos de família e comunidade.

17. Fortalecer a Rede Ibero-americana de Pesquisa em Medicina de Família e Comunidade (IBIMEFA) para fomentar a pesquisa, a formação de pesquisadores em Medicina de Família e Comunidade e a divulgação de novos conhecimentos em Medicina de Família e Comunidade e Atenção Primária à Saúde, em interação com outras redes de pesquisa na Ibero-América e no mundo, promovendo a questão para os órgãos internacionais, órgãos governamentais de saúde e de educação dos países da região.

18. Potencializar o uso das Tecnologias da Informação e Comunicação nos processos de pesquisa e difusão em Medicina de Família na região; por meio da criação de bases de dados de informação de pesquisas, publicaçóes, consultores, revisores e pesquisadores em Medicina de Família e Comunidade.

19. Incentivar o compromisso de todos os atores envolvidos na coparticipação do financiamento para a geração e difusão do conhecimento, através da pesquisa especializada em Medicina de Família e Comunidade; a mesma que implica uma responsabilidade das organizaçóes ibero-americanas de Medicina de Família e Comunidade para evitar que tais pesquisas sejam influenciadas por interesses comerciais.

20. Incentivar as universidades e autoridades formadoras de profissionais da saúde para que fortaleçam o ensino e pesquisa em Atenção Primária e em Medicina de Família e Comunidade, tanto nos estudantes como na pós-graduação.

21. Promover que as sociedades de Medicina de Família de Comunidade da região tenham maior envolvimento nos processos técnico-políticos de fortalecimento do primeiro nível de atenção e da Medicina de Família e Comunidade em seus países, assim como nos processos de qualificação e desenvolvimento profissional contínuo, com certificaçáo e recertificação de seus membros.

22. Recomendar aos médicos de família e comunidade, para que junto com os demais integrantes da equipe de APS nos países da região, tornem visível e evidenciem a transcendência da especialidade de Medicina de Família e Comunidade como primeiro contato e acompanhamento contínuo nos sistemas de saúde, aos membros da sociedade civil.

23. Promover a criação do Observatório de Medicina de Família e Comunidade na região com a participação da Wonca e Wonca Iberoamericana-CIMF, para fortalecer a identidade e a especialidade e que se constitua em uma ferramenta relevante para a tomada de decisóes dos governos, os órgãos internacionais, a academia e a comunidade.

Nota da RBMFC: o documento original encontra-se disponível em http://www.salud.gob.ec/carta-de-quito-v-cumbreiberoamericana-de-medicina-familiar/

Tradução: Rogério Machado (Secretário da SBMFC). 